SUPPORTING INFORMATION for:

\title{
Role of Oligoethylene Glycol Side Chain Length in Responsive Polymeric Nanoassemblies
}

Kishore Raghupathi ${ }^{\perp}$, Vikash Kumar ${ }^{\perp}$, Uma Sridhar', Alexander E. Ribbe ${ }^{2.4}$, Huan He and S. Thayumanavan ${ }^{13,4} *$

'Department of Chemistry, ${ }^{2}$ Department of Polymer Science and Engineering, ${ }^{3}$ Molecular and

Cellular Biology Program, ${ }^{4}$ Center for Bioactive Delivery, Institute for Applied Life Sciences,

University of Massachusetts Amherst, MA 01003

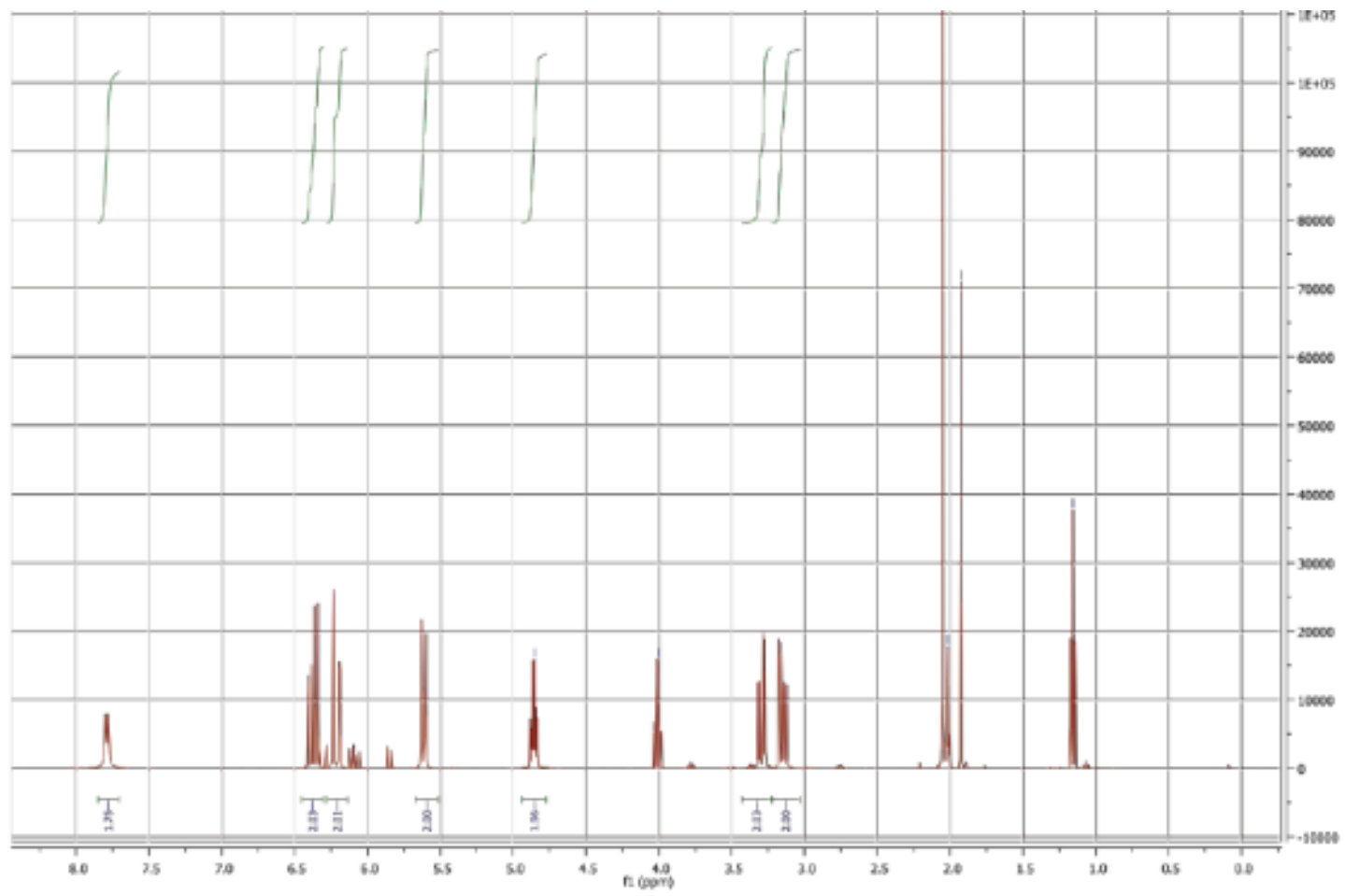

Figure S1: 'H NMR of redox responsive crosslinker

\footnotetext{
${ }^{\perp}$ These authors contributed equally to this manuscript.
} 


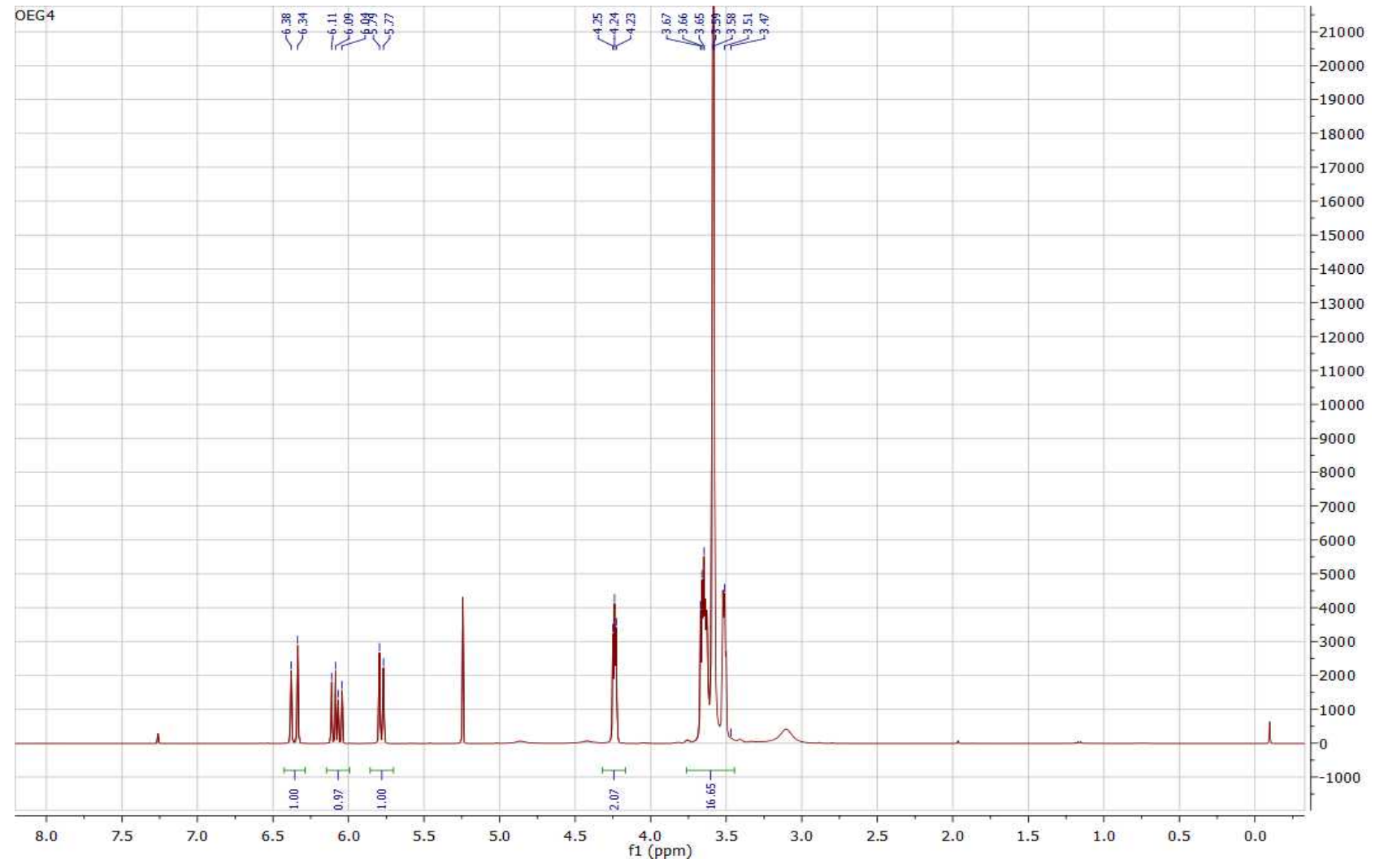

Figure S2: 'H NMR for tetraethyleneglycol acrylate 


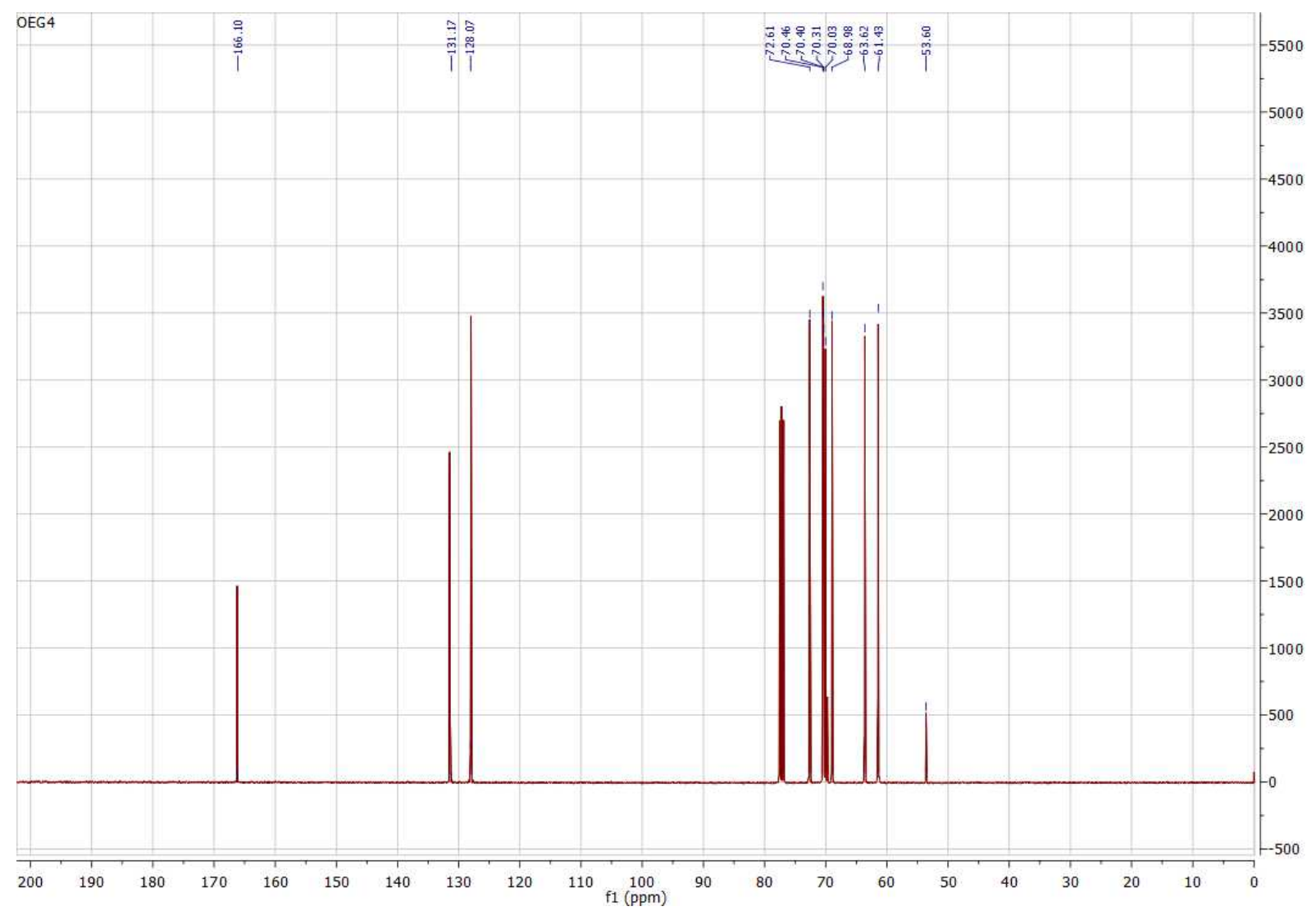

Figure S3: ${ }^{13} \mathrm{C}$ NMR of tetraethyleneglycol acrylate 


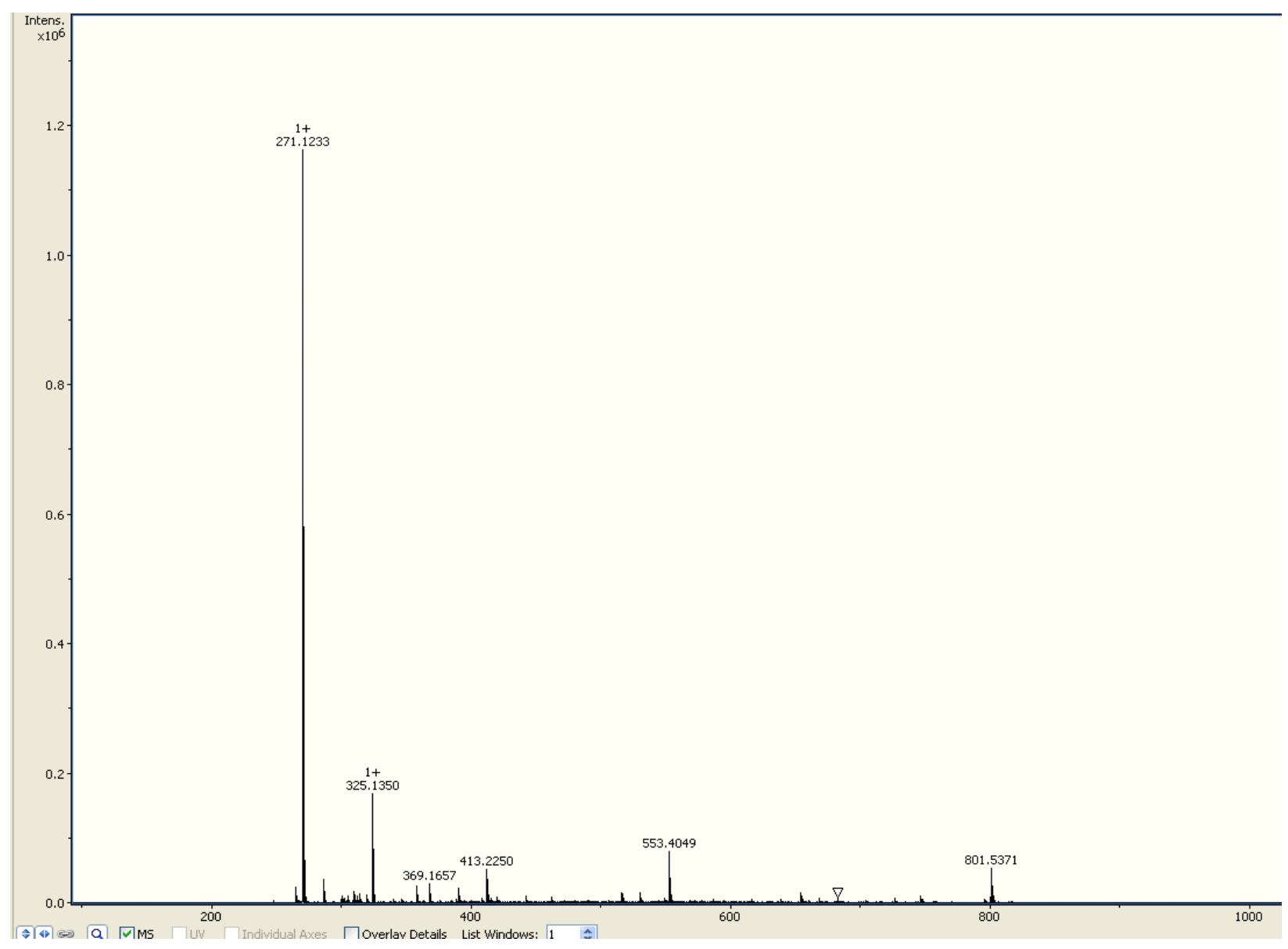

Figure S4: ESI MS of tetraethyleneglycol acrylate

$\mathrm{MW}=$ tetraethyleneglycol acrylate $+\mathrm{Na}^{+}=271.12$ 


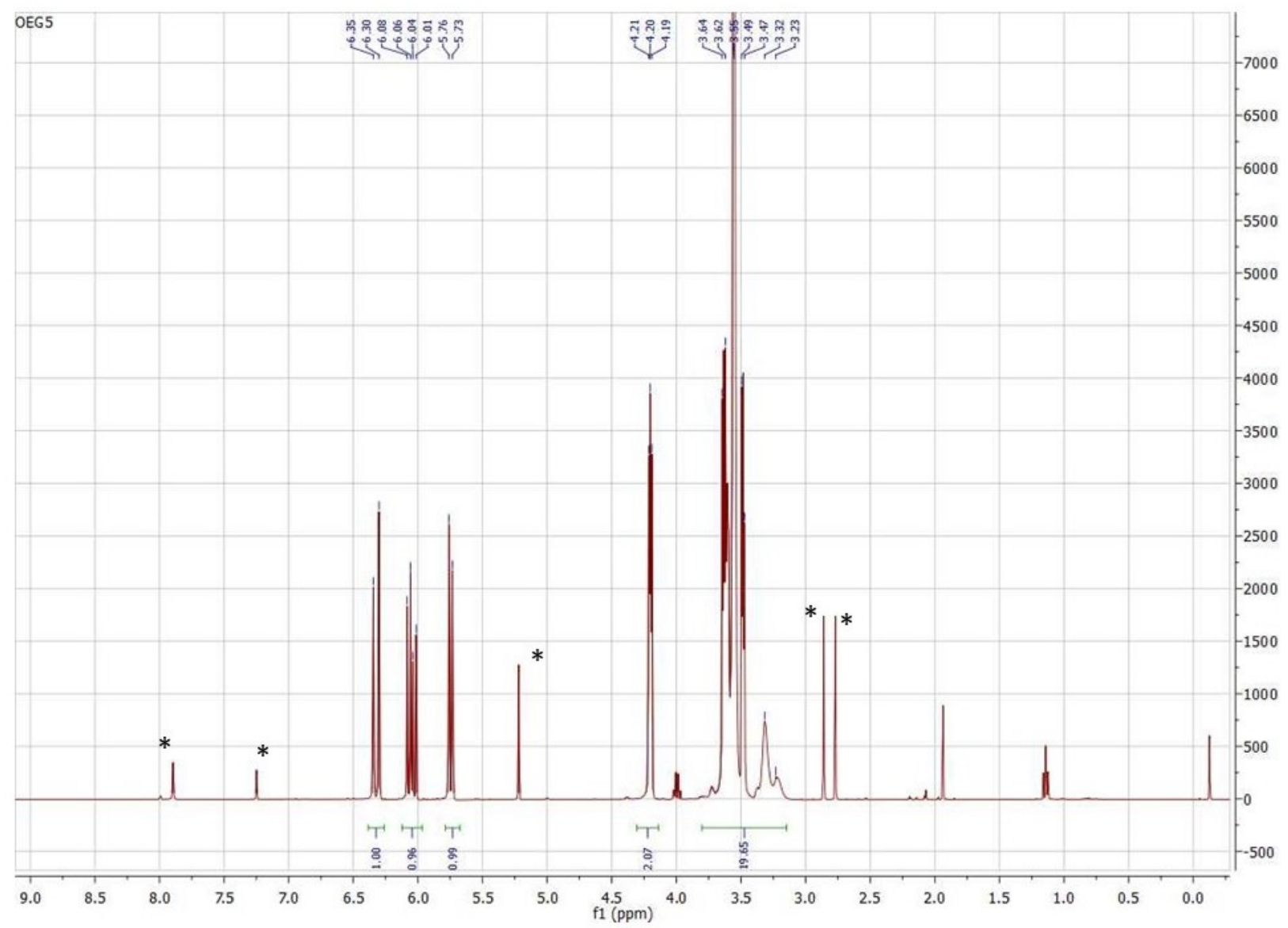

Figure S5: 'H NMR of pentaethyleneglycol acrylate 


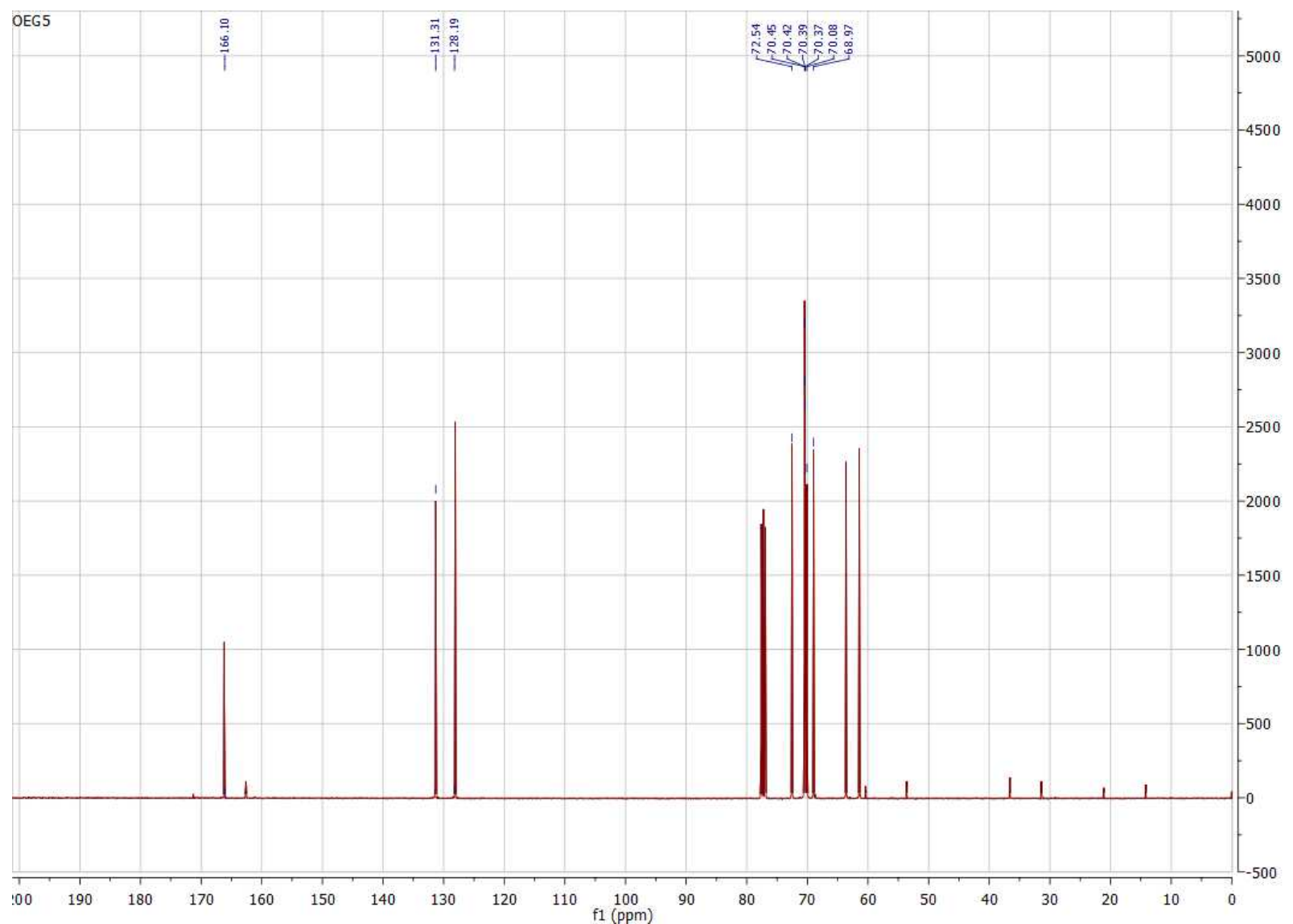

Figure S6: ${ }^{13} \mathrm{C}$ NMR of pentaethleyneglycol acrylate 


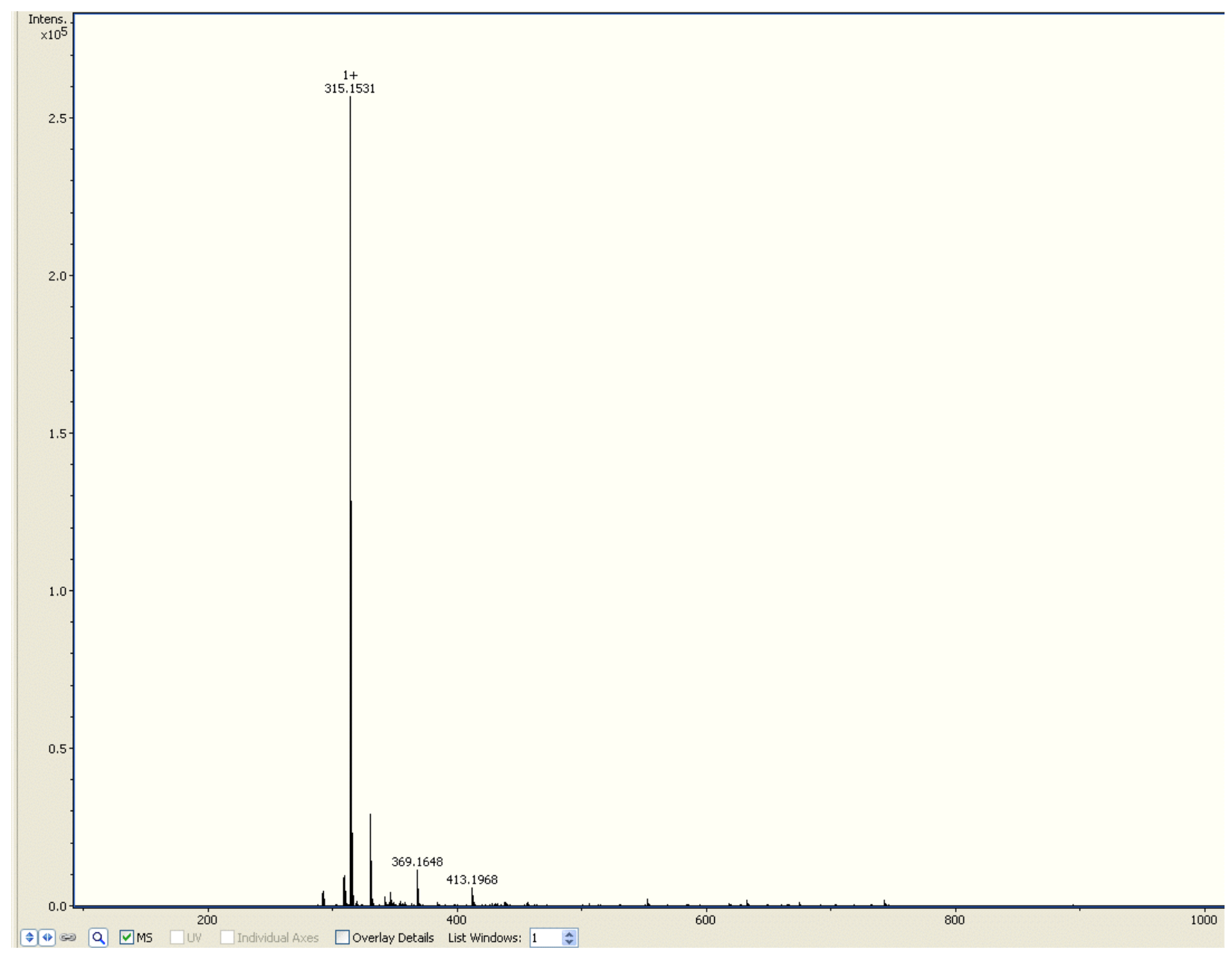

Figure S7: ESI MS of pentaethyleneglycol acrylate

$\mathrm{MW}=$ pentaethyleneglycol acrylate $+\mathrm{Na}^{+}=315.15$ 


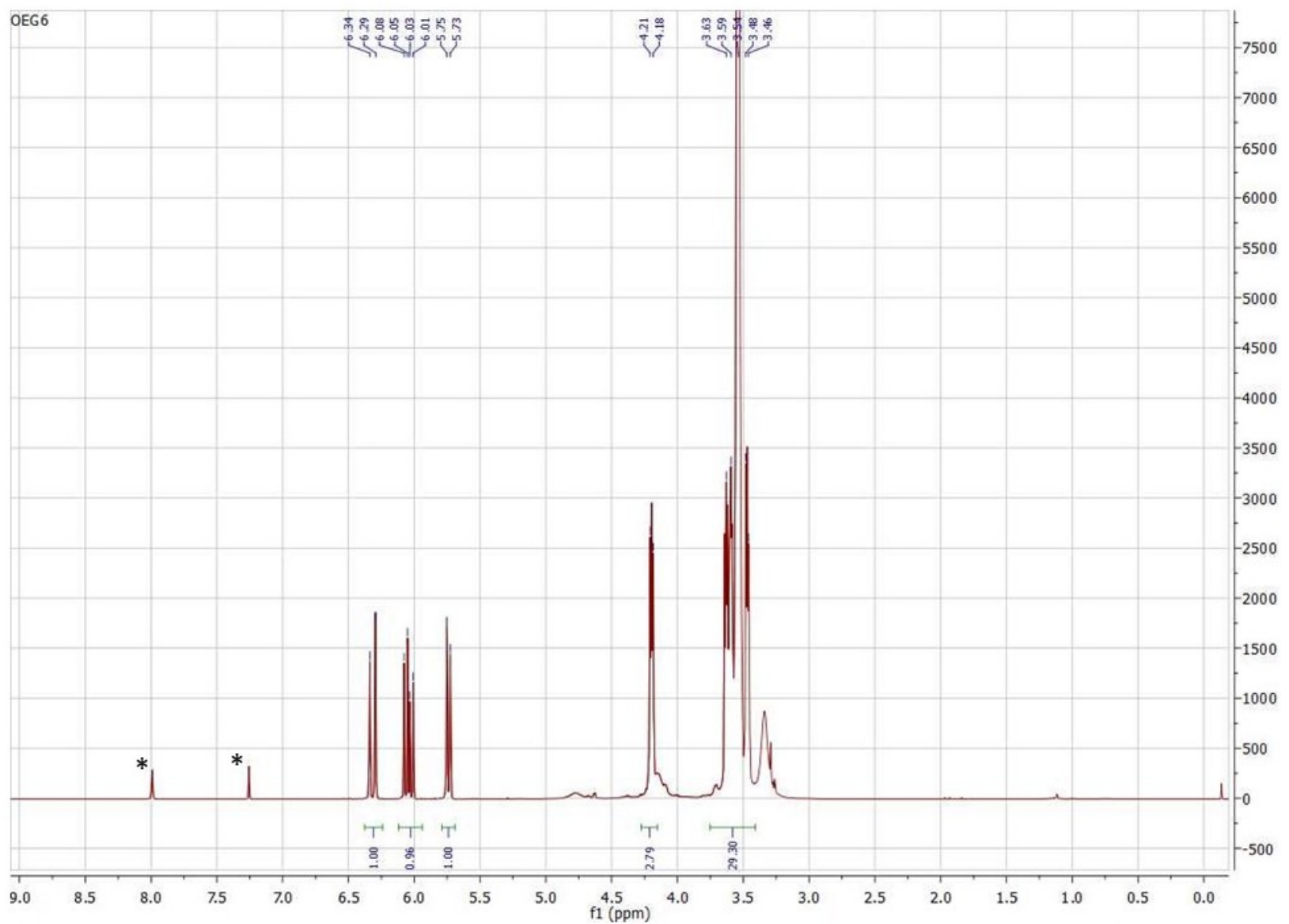

Figure S8: 'H NMR of hexaethyleneglycol acrylate 


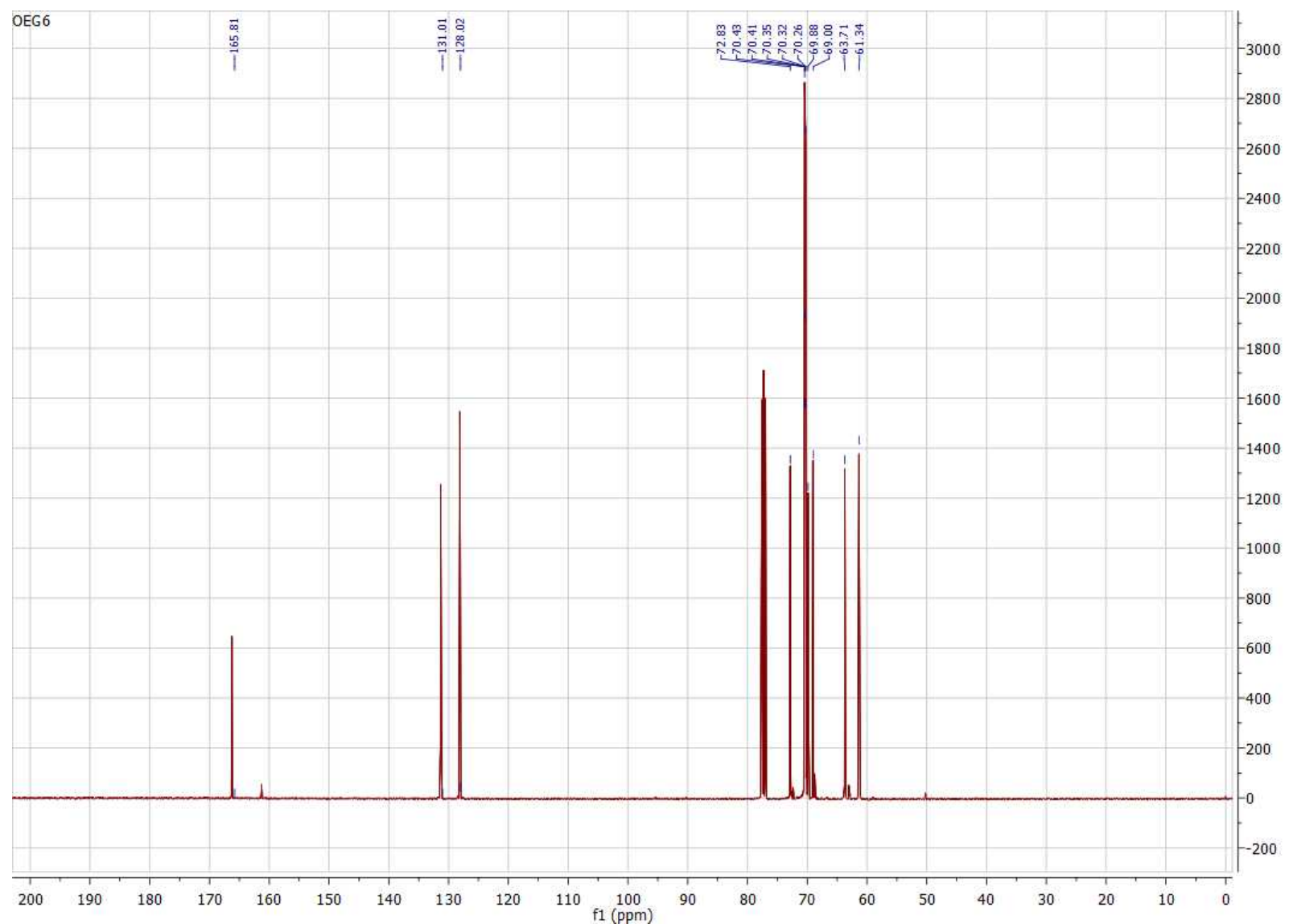

Figure S9: ${ }^{13} \mathrm{C}$ NMR of hexaethyleneglycol acrylate 


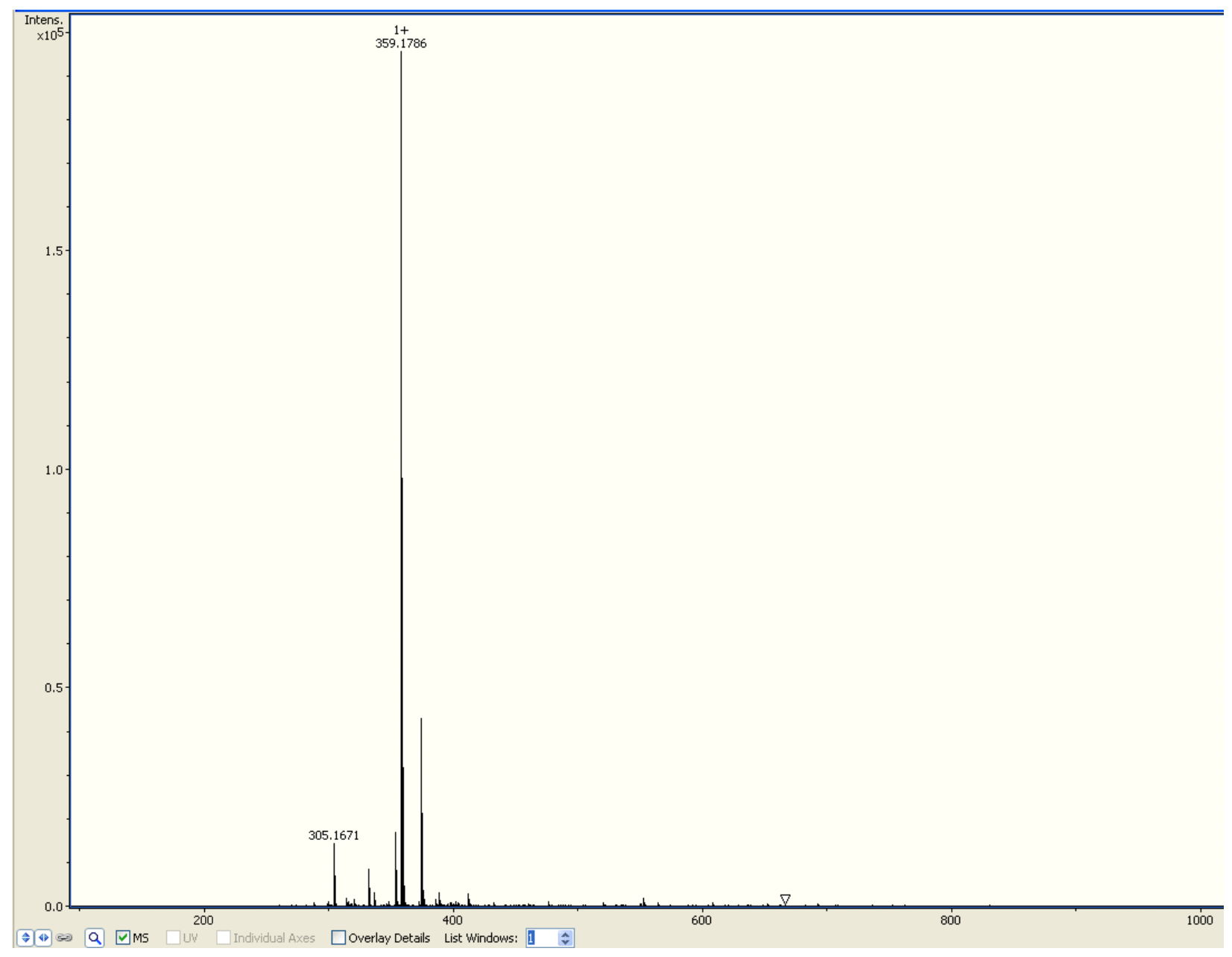

Figure S10: ESI MS of hexaethyleneglycol acrylate

$\mathrm{MW}=$ hexaethyleneglycol acrylate $+\mathrm{Na}^{+}=359.17$ 

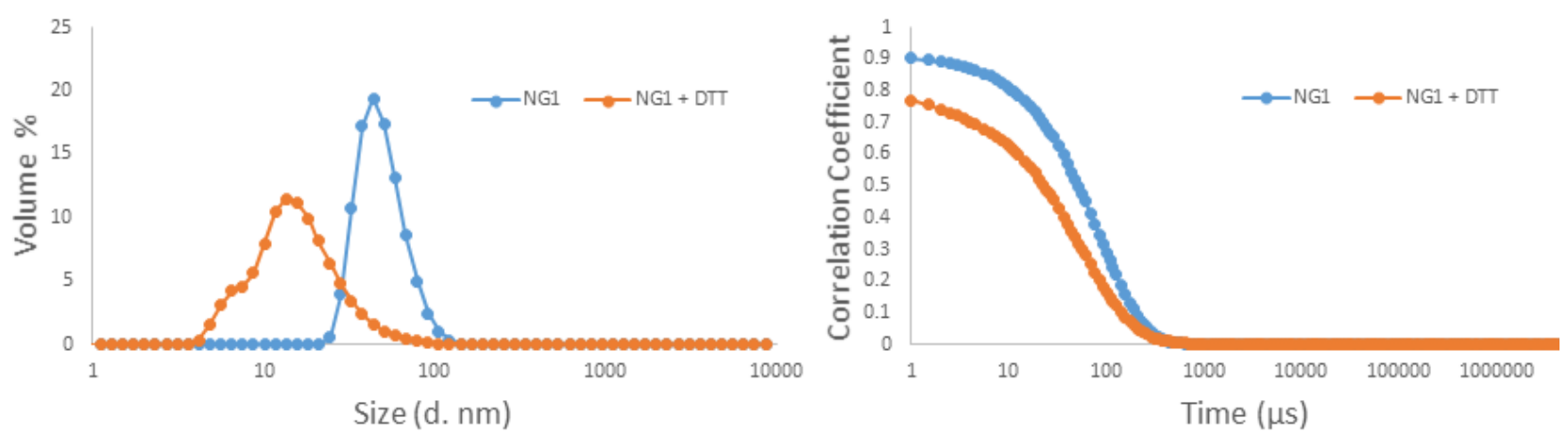

Figure S11: DLS plot and correlation function of NG1 before and after adding DTT
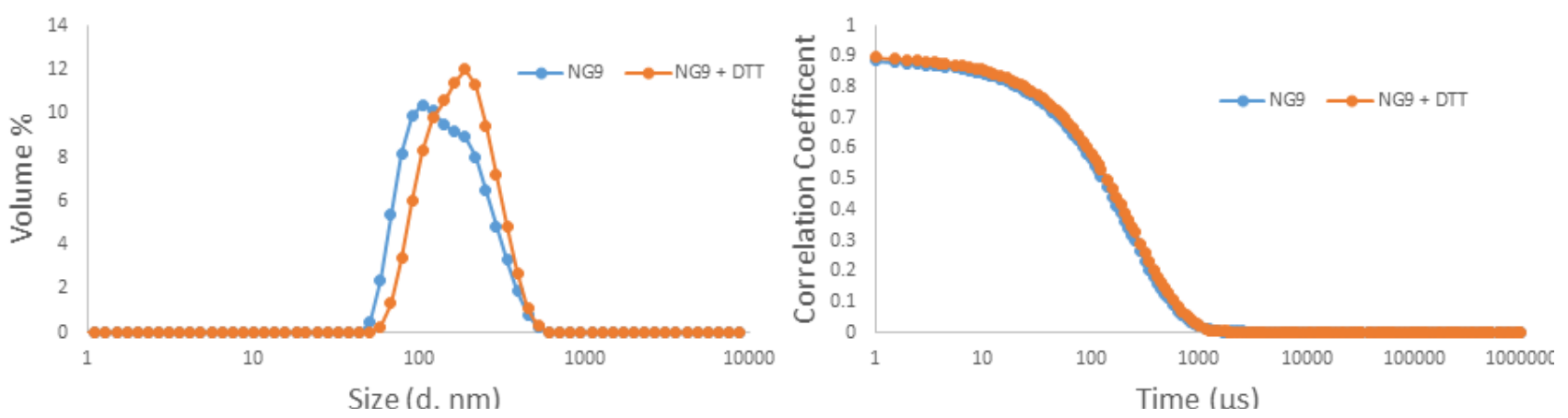

Figure S12: DLS plot and correlation function of NG9 before and after adding DTT
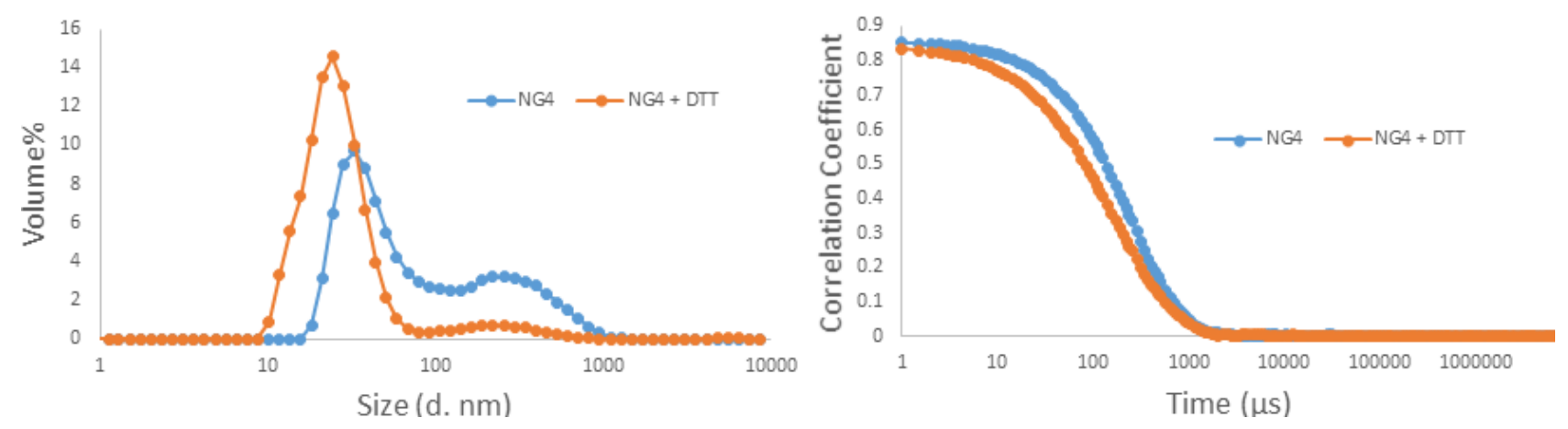

Figure S13: DLS plot and correlation function of NG4 before and after adding DTT 

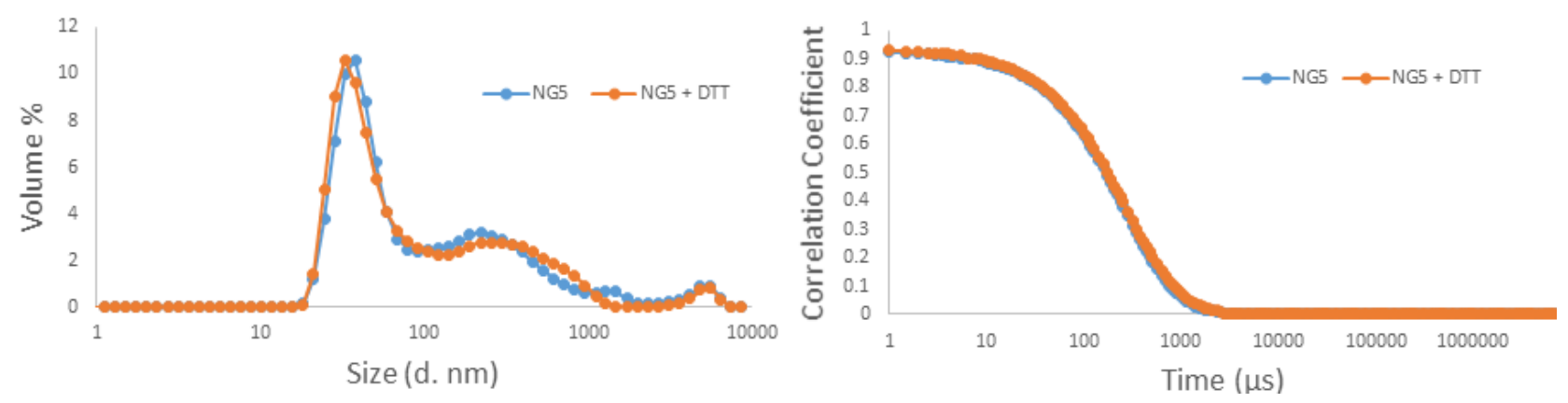

Figure S14: DLS plot and correlation function of NG5 before and after adding DTT
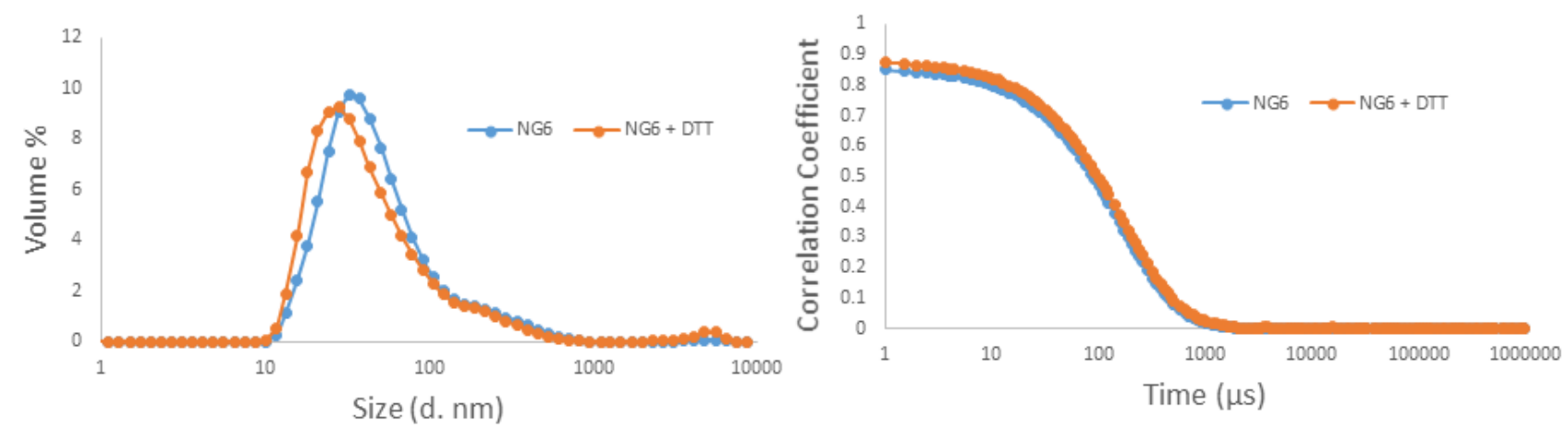

Figure S15: DLS plot and correlation function of NG6 before and after adding DTT 

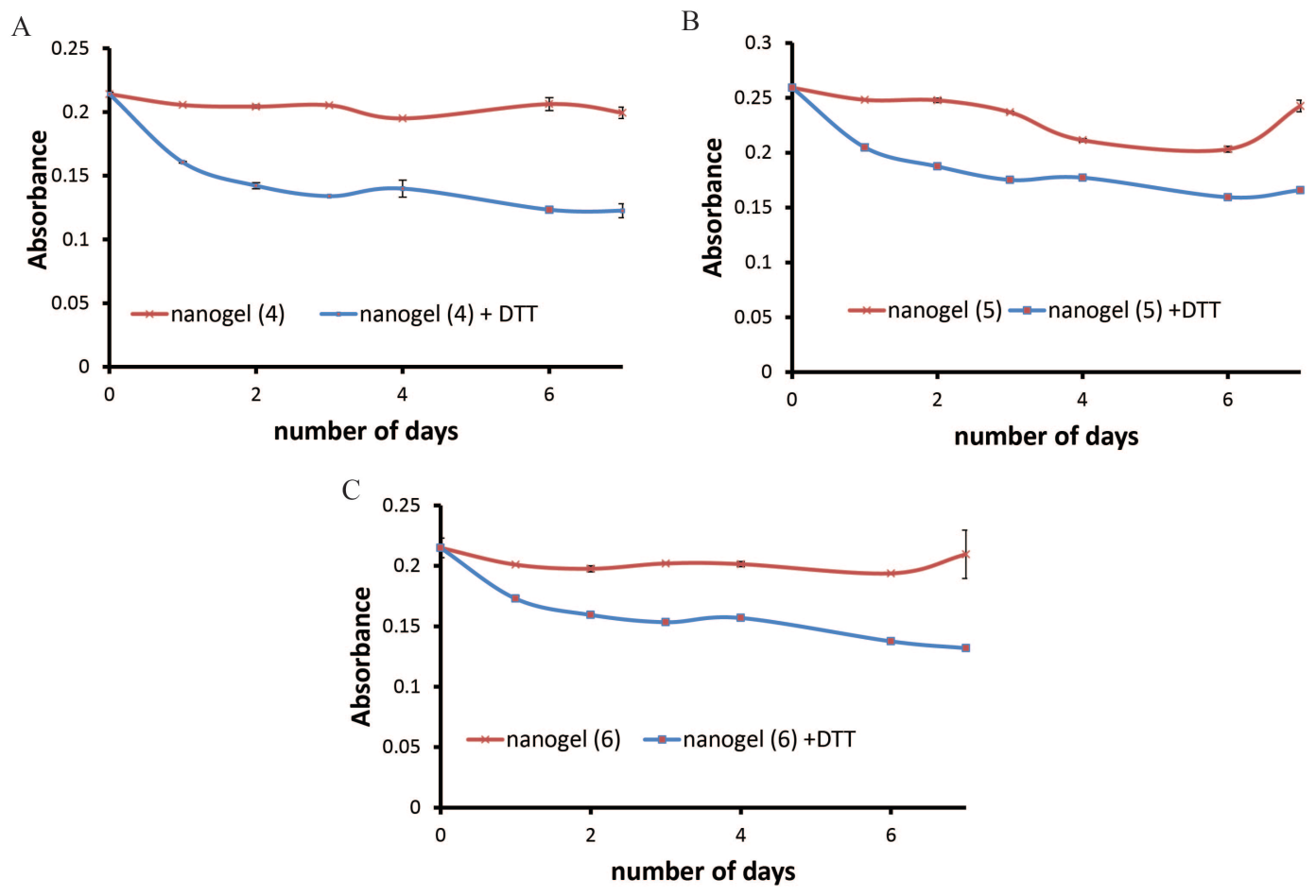

S16: Dye release study of (A) nanogel (4), (B) nanogel (5), and (C) nanogel (6) with and without redox trigger.
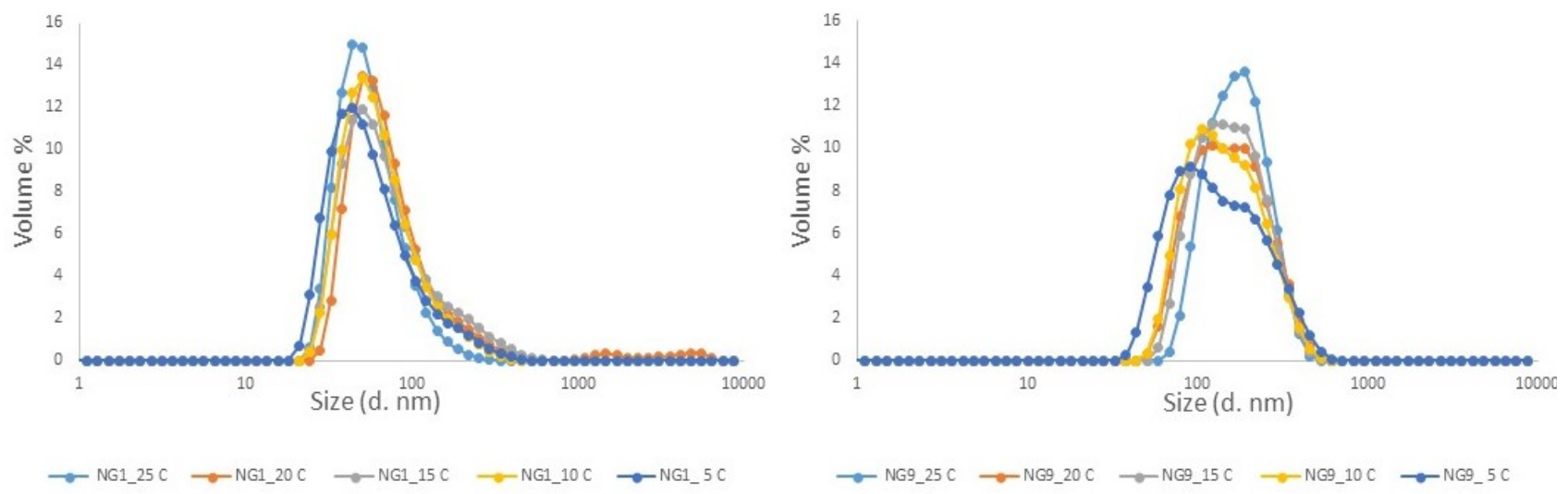

S17: Effect of temperature on the size of NG1 and NG9 at $25^{\circ} \mathrm{C}, 20^{\circ} \mathrm{C}, 15^{\circ} \mathrm{C}, 10^{\circ} \mathrm{C}, 5^{\circ} \mathrm{C}$ 